\title{
ENCENANDO AMIZADE: PÍLADES E ORESTES NA TRAGÉDIA
}

\author{
ORLANDO LUIZ DE ARAÚJO \\ Departamento de Letras Estrangeiras \\ Universidade Federal do Ceará
}

\begin{abstract}
Resumo: Os poetas épicos são pouco explícitos sobre a relação de amizade entre Pílades e Orestes. A poesia trágica, entretanto, ocupar-se-á do tema. N'As Coéforas, de Ésquilo, é Pílades quem aconselha o amigo sobre o que fazer; em Electra, a despeito do silêncio que Sófocles imprime a Pílades, esse é ainda o protetor e fiel amigo de Orestes. Por fim, Eurípides, em Electra e Orestes, menciona a afeição entre Pílades e Orestes. Desse modo, pretende-se, mostrar a importância da amizade no mito antigo que envolve Orestes e, em especial, nas tragédias acima.
\end{abstract}

Palavras-chave: Tragédia grega, amizade, Orestes e Pílades

\section{Introdução}

Na genealogia dos atridas, Pílades figura como filho de Estrófio, da Fócia, e de Anaxíbia, uma irmã de Agamêmnon. Pílades é, consoante sua procedência, primo de Orestes. A união dos dois, a exemplo da dos irmãos Castor e Pólux, não se dá apenas mediante o grau de parentesco, mas se estende além dos laços filiais, alcançando os laços de afeição, como a amizade de Pátroclo e Aquiles, a de Niso e Euríalo e, exemplarmente, a de Dâmon e Pítias, ${ }^{1}$ modelos nobres de amigos e de amizades.

Na narrativa mítica, Orestes aparece ainda criança. No episódio de Mísia, quando os gregos, prestes a partir para Troia, estão à busca de Télefo, suspeito de

1 Dâmon e Pítias são dois filósofos pitagóricos de Siracusa. Dâmon, tendo sido condenado à morte pelo tirano Dioniso I, recebeu desse o direito de voltar a sua casa, a fim de organizar seus negócios, com a promessa de que voltaria ao local da execução na hora marcada. Pítias, seu amigo, penhorou-se como garantia, pois caso Dâmon não retornasse a tempo, sofreria a penalidade no lugar do amigo. Mas Dâmon retornou no momento indicado. Dioniso ficou tão admirado com a fidelidade da amizade dos dois, que perdoou Dâmon que, junto com o amigo, obteve a amizade do rei. (Plutarco, Valérius Máximo, 4,c.7). 
ser um espião, Orestes é feito refém de Télefo. $O$ intento de Télefo, no entanto, era o de ser atingido, outra vez, pela lança de Aquiles, pois somente assim poderia se curar e, na perseguição, ao ver Orestes, Télefo o ameaça de morte, caso Aquiles não o curasse. Orestes também aparece como uma criança, no episódio de Áulis, no momento do sacrifício da sua irmã Ifigênia.

$\mathrm{Na}$ épica grega, Homero menciona duas vezes o nome de Orestes, na Ilíada $(9.142,284){ }^{2}$ quando Agamêmnon promete a Aquiles tratá-lo como a Orestes, o filho bem amado, que vive cercado de grande opulência, caso voltem vivos aos campos de Argos, e Aquiles aceite retornar ao campo de batalha.

Todas as referências feitas a Orestes, na Ilíada, apresentam-no em Argos, ainda menino, vivendo uma infância opulenta e feliz ao lado da mãe, mas sempre na ausência do pai que se encontra em Troia, como comandante dos gregos, para resgatar Helena, a esposa de seu irmão Menelau. Na Odisseia, porém, Homero pinta outro quadro de Orestes. Agora, já adulto, passará a figurar como o membro do palácio amaldiçoado dos atridas, cuja maldição tem sua origem na transgressão de Tântalo. Já na épica, Orestes é representado longe de Argos, como exilado e matador de Egisto. Na Odisseia, Orestes é mencionado seis vezes (Od. 1.30, 40, $298 ; 3.306 ; 4.546)^{3}$ e, de todas elas, apenas uma única vez não aparece relacionado à morte de Egisto (11.461). ${ }^{4}$ Homero parece reconhecer que a vingança do "divino

2 Se para os campos ubérrimos de Argos de Acaia voltarmos, seja meu genro; honrá-lo-ei, sem fazer distinção, como a Orestes, meu filho amado, que vive cercado de grande opulência. (Ilíada, 9.141-43, 284, trad. de Carlos Alberto Nunes)

3 (...) que se lembrou em sua alma de Egisto, de formas perfeitas, Que de Agamémnone o filho, o notável Orestes, matara. (Odisseia, 1.29-30, trad. Carlos Alberto Nunes)

(...) Hermes de tudo a avisar, o brilhante e certeiro vigia, que, nem se unisse à mulher, nem, tampouco, o marido matasse, pois a vingança do filho de Atreu lhe viria de Orestes, quando crescesse e saudades sentisse da terra nativa. (Ibidem, 1.38-41)

Ou não soubeste da fama que Orestes divino entre os homens veio a alcançar, por haver dado a morte ao Tiestíada Egisto, que, com traiçoeira artimanha, matara seu pai muito ilustre? (Ibidem, 1.298-300)

(...) retorna de Atenas

O ínclito Orestes, e a Egisto matou, o assassino do Atrida. (Ibidem, 3.306-7)

encontrá-lo-ás ainda vivo, talvez; ou quem sabe se Orestes já o imolou; para o enterro é possível com tempo chegares. (Ibidem, 4.546-7)

4 Porquanto Orestes ilustre na terra ainda se acha com vida. (Ibidem, 11.461). 
Orestes" contra Egisto que seduziu Clitemnestra, primeiramente, contra sua vontade, e matou Agamêmnon, astuciosamente, no seu retorno de Troia, para se apoderar do poder, é um ato justo. O assassínio da mãe, representada como "odiosa", é citado de forma secundária e indireta. Somente no canto 11.461, atribui-se responsabilidade de Clitemnestra no assassinato de Agamêmnon.

Em Hesíodo, no Catálogo das Mulheres (fr.23, v.28-30 Merkelbach-West), ${ }^{5}$ a vingança de Orestes é também conhecida. O poeta, ao contrário de Homero, apresenta a morte de Clitemnestra no mesmo plano que a de Egisto. Nos Nóstoi, ${ }^{6}$ conhecido pelo resumo de Proclo, temos a última referência, na literatura épica, da vingança de Orestes. Com relação a Homero e a Hesíodo, que não põem Pílades ao lado de Orestes, aqui, ele participa da punição. Assim, diferentemente de Homero, que apresenta Orestes exilado em Atenas, nos Nóstoi, devemos supor que seu exílio foi na Fócida, cidade de Pílades.

Segundo Píndaro (474-454), na Pítica $11.15 \mathrm{ss},{ }^{7}$ Orestes fugiu de Fanoteu, no Monte Parnaso, onde o rei Estrófio passou a cuidar dele, ${ }^{8}$ até a idade de 20 anos, para que retornasse a Argos e pudesse vingar a morte do pai. Nesse retorno, já o vemos ao lado de Pílades, constituindo, doravante, uma amizade exemplar. A despeito do silêncio dos poetas épicos a respeito de Pílades, é no drama que a amizade de Orestes e de Pílades se encena e se consolida.

5 E por último, no palácio, Clitemnestra de olhos sombrios deu à luz, submetida a Agamêmnon, ao divino Orestes, que, em plena juventude, vingou a morte do pai e matou a mãe arrogante com o impiedoso bronze.

(Catálogo das Mulheres, frag.23, vv.27-30, trad. de Wilson Alves Ribeiro Jr.).

6 Após a morte de Agamêmnon por Egisto e Clitemnestra, vem a vingança de Orestes e Pílades (Chrestomathia, 301-3, tradução nossa).

(...) sobre ella poniendo tercera corona, al vencer en los campos fecundos de Pílades, el amigo del laconio Orestes. (Píticas, 11.14-16, trad. de Alfonso Ortega).

Outros poetas líricos, como Xanto (éd. Page, frag.699-700) e Estesícoro (éd. Page, 210. 219) também trataram do tema da vingança de Orestes. O segundo, retomando o primeiro, escreveu uma Oresteia. Muitos elementos da obra de Estesícoro são tomados de empréstimo à obra do dramaturgo Ésquilo.

8 De acordo com Píndaro, é no Parnaso que Orestes passa seu exílio. Em Píndaro, nenhuma menção é feita a Electra, daí ele ter sido salvo pela ama Arsinoé. E ainda, contrariamente à tradição, Orestes não ser argivo, mas lacedemônio. 


\section{2. Ésquilo. Coéforas}

O drama despende grande atenção ao tema da vingança de Orestes e não descura da participação de Pílades, mesmo quando este se posta, silenciosamente, na cena, como em Electra, de Sófocles. Em Coéforas, de Ésquilo, Pílades é mencionado em três momentos da tragédia (vv.20, 562, 899), ${ }^{9}$ como personagem muda, e intervém uma única vez, quando Orestes hesita se deve ou não sacrificar a própria mãe. Neste momento, Pílades o faz relembrar os vaticínios do deus délfico. Ésquilo menciona, no prólogo, a participação de Pílades como um amigo de Orestes. Ao chegarem à cidade, Orestes e Pílades, ignorantes dos eventos que estão acontecendo, buscam se informar sobre tais acontecimentos. Assim, Orestes conclama Pílades a acompanhá-lo, porque ambos precisam saber o que significa a procissão de mulheres pelo palácio. No contexto, o uso da primeira pessoa do aoristo do verbo mantháno, mátho, seguido de saphõs, claramente, revela o ambiente em que os dois amigos vão penetrar, a saber, o campo inimigo que será, cuidadosamente, revisado pelo adversário. Neste sentido, a participação de Pílades, caracterizado como o amigo leal, é fundamental e deve a Homero, na Ilíada, seus créditos, quando o aedo impele Diomedes a convidar o amigo para entrar no campo dos adversários troianos. Sozinho, como reconhece o herói homérico, arrisca-se mais do que acompanhado, visto que a agudeza de espírito e a ação são eficientes, quando planejadas em conjunto, ao passo que para a ação solitária, a inteligência e a ação se tornam ineficazes.

Em 562, Orestes se prepara para entrar, de fato, no palácio. Há um ensaio geral, no qual todos os atores assumem seus papeis. Nesta cena, Orestes, codirigido pelas palavras do Coro e do homem que também se vincula como se fosse um pai para ele, o Preceptor é, por sua vez, também, o 'diretor' da cena. E, após o imperativo coral eksegoû (explica, v. 552) seguido da palavra phílois (aos amigos), Orestes deverá fornecer as instruções de como devem atuar diante dos inimigos, mas não se esquece de que a companhia aliada de Pílades é crucial para a realização do plano. Para que possam ter êxito, têm apenas que narrar bem o roteiro que desempenharão - o qual resulta fácil para Orestes, por estar cercado, de todos os lados, de caras alianças, como a do Coro, no sentido de que este oculte o pacto,

9 Ó Pílades, afastemo-nos para sabermos

Claro que procissão de mulheres é esta. (Coéforas, vv.20-21, trad. de Jaa Torrano)

com aspecto de hóspede e armas completas

chegarei à áulica porta com este homem

Pílades, como hóspede e aliado da casa. (Ibidem, vv.560-62)

Pílades, que fazer? Temo matar a mãe. (Ibidem, v.899) 
e a de Pílades. Como no jogo cênico, em que tudo é ambíguo, o disfarce de Pílades e Orestes como estrangeiros amplia ainda mais tal ambiguidade, ao pensarmos em questões metateatrais; ora, para invadir o território do inimigo, os dois amigos aproximam-se como hóspedes e aliados, e são recebidos de acordo com as regras da boa hospitalidade, mas ambos transgridem as regras: Pílades, por ser efetivamente estrangeiro com relação ao palácio dos atridas, pela hospedagem; e Orestes, por ser verdadeiramente filho, por promover a vingança. A cena dentro da cena que antecedente o plano fatal de Orestes termina com a exortação a Pílades para que este se mantenha alerta ao palácio:

Agora, mantém-te alerta dentro do palácio para que tudo concorra de modo coerente. ${ }^{10}$

Além de amigo, Pílades é a garantia que Orestes tem de que a vingança acontecerá. Além de amigo, ele é o sentinela que tudo guarda, a fim de que a missão seja coerente. Em 894, após ter morto Egisto, Orestes se dirige a Clitemnestra nos seguintes termos:

Amas o homem? Assim na mesma tumba jazerás e nem morto não o traias nunca. ${ }^{11}$

Às rudes palavras do filho, Clitemnestra opõe-se, apelativamente:

Pára, filho, e respeita, criança, este

seio em que muitas vezes já sonolento

sugaste com as gengivas nutriente leite. ${ }^{12}$

Diante do apelo da mãe, Orestes titubeia na ação e medita o quanto é vergonhoso matar uma mãe. É, então, aos conselhos de Pílades que ele recorre, ao perguntar: Pyláde, ti dráso; (v.899). Na peça, pela primeira e última vez, Pílades fala. Não emite nenhum juízo valorativo, tampouco aponta o caminho que Orestes deve seguir; todavia, de forma quase oracular, apenas reaviva, no espírito de Orestes, o sentido religioso das palavras de Apolo:

\footnotetext{
10 Ibidem, vv. 579-80.

11 Ibidem, vv.894-95.

12 Ibidem, vv.996-98.
} 
Onde no porvir os vaticínios de Lóxias

dados em Delfos e os fiéis julgamentos?

Tem por hostis a todos mas não aos Deuses. ${ }^{13}$

As palavras de Pílades retiram Orestes da dúvida, pois julga (kríno, na primeira pessoa) que o amigo está com a razão e que o aconselha bem (paraineîs, na segunda pessoa dirigindo-se diretamente a Pílades). A palavra do amigo trazida à tona, ainda que na sua expressão humana, toma a forma de uma palavra divina. Assim, neste jogo de se e de moi (de "te" e de "mim", ou seja, o julgamento que leva um "eu" a agir, a partir da vitória de um "tu", e o elogio do "eu" a um "tu"), inscreve-se na máxima do Pseudo-Plutarco que vê o amigo como um outro eu. Isto se aplica, mormente, na relação entre Pílades e Orestes, nesta tragédia, sobretudo se aceitarmos a ruptura do silêncio de Pílades como o ponto máximo a que atinge a fúria misturada com a dúvida de Orestes face ao matricídio, desencadeado pela forma ti dráso; (que farei?).

\section{Sófocles. Electra}

Na tragédia de Sófocles, especialmente, na Electra ${ }^{14}$ o par Orestes e Pílades segue a tradição de Ésquilo que coloca Orestes ao lado de Pílades; mas, ao contrário de Ésquilo, que permite que Pílades rompa o silêncio, embora possamos pensar que a suspensão do silêncio, em Coéforas, funcione como recurso interpretativo do autor; em Sófocles, o silêncio de Pílades não é mera eloquência, sobretudo para as inferências dos espectadores. Em Sófocles, somente duas referências são feitas a Pílades: primeiramente, pelo Preceptor de Orestes, que o considera o mais caro dos hospedeiros/hóspedes (phíltate xénon, v.16), já na segunda referência, Orestes, Pílades e o Preceptor estão prestes a entrar no palácio. Neste momento, Orestes adverte a Pílades que não necessitam mais de palavras, mas de ações.

Pílades, nosso trabalho não requer longos discursos, mas, de entrarmos o mais rápido possível na casa... ${ }^{15}$

13 Ibidem, vv.900-2.

14 Nesta tragédia de retorno, o prólogo apresenta, numa primeira cena, aqueles que vêm do exterior para realizar a vingança. Orestes, acompanhado de seu amigo Pílades e de seu Preceptor, chega, ao alvorecer diante do palácio ancestral, em Micenas. Duas personagens, somente, intervêm, o Preceptor e Orestes, porque Pílades é representado por um ator mudo.

15 Sófocles. Electra, vv.1372-74, tradução nossa. 
Vemos que tanto em Ésquilo, quanto em Sófocles, Pílades desempenha o papel adequado para o amigo que age ao lado do amigo, mas nunca o papel de conselheiro. Não podemos tomar como um conselho as palavras de Pílades em Coéforas, visto que ele profere uma máxima, uma espécie de reflexão geral que não se aplicaria meramente ao contexto proposto, tampouco a Orestes, mas a qualquer ser piedoso e temente das ordens do deus Apolo. Portanto, o objetivo é de apenas lembrar a Orestes do que não deve esquecer.

Os versos acima (1372-1374) retomam o discurso inicial do Preceptor, em $1-22$, quando demonstra sua preferência pelas obras, mais que pelas palavras. Se considerarmos a predileção pelo feito em detrimento da palavra, um tema recorrente na peça, e se observarmos a primazia que o grego lhe dá, incluindo nela o pensamento, o exame detido das coisas e as sutis distinções morais, podemos inferir que a amizade de Orestes e Pílades, modeladas pelo desejo de vingança, assim como a participação do Preceptor na vingança, não constituem, pelo menos em Sófocles, exemplos de admiração. Isto se torna ainda mais evidente, quando Sófocles silencia sua personagem, uma vez que essa nada teria a contribuir, senão pela força do braço, com a ação. Porém, ao mesmo tempo em que faz Pílades calarse, oferece a Orestes a possibilidade da teorização, quando Apolo recomenda-lhe que aja sozinho, pela astúcia (dóloisi, v.37), não pela força do braço (kheirós, v.37).

A habilidade de Pílades com a mão, mais que com a palavra, também se apresenta em Electra, de Eurípides. Nesta tragédia, Pílades, ainda em silêncio, aparece como o primeiro dos homens para Orestes (próton anthrópon, v.82), a quem ele julga (nomízo, v.83) pistón, phílon e xénon (fiel, amigo e hospedeiro/hóspede). A sequência de adjetivos, culminando com a palavra xénon, evidencia não apenas a relação de philía estabelecida entre Orestes e Pílades, mas a relação de reciprocidade que envolve as regras da hospitalidade, positivando-a. Único (mónos, v.84) dentre os amigos (phílon, v.84) que permanece ao lado de Orestes, Pílades constitui o seu duplo-complementar. Ora, Orestes se distingue de Pílades ao dizer que este é um amigo, portanto, um outro eu, e um hospedeiro/hóspede, um outro Outro; todavia o adjetivo mónos assinala a identidade dos amigos, quando um permanece ao lado do outro, mesmo nas condenações da sorte, como assinala Orestes para o amigo.

\section{Eurípides. Orestes}

No prólogo do Orestes, Electra menciona sua participação, juntamente com Orestes, e o auxílio de Pílades, na vingança dos matadores de Agamêmnon. Mais uma vez, vemos a inclinação de Pílades para o uso da força e da decisão pelo braço. 
Quando o mensageiro pergunta a Orestes quem estava ao seu lado, no dia em que Orestes, pela primeira vez, sofreu os sintomas da doença que lhe persegue, é Pílades, o amigo, que estava lá, assim como estivera e ajudara a matar Clitemnestra (v.406).${ }^{16}$ Em 726, ${ }^{17}$ Orestes, em disputa com Menelau, aponta a ingratidão do tio, face aos benefícios que Agamêmnon lhe emprestara no passado, quando foi a Troia para resgatar Helena. Orestes cobra do tio o princípio grego de reciprocidade que manda ajudar os amigos e prejudicar os inimigos. Para Orestes, Menelau parece desconhecer tal doutrina. Assim, Menelau participa do grupo dos que desprezam aqueles que caíram em ruínas.

Nessa passagem, Orestes reduz Menelau à categoria de áphilos (v.721), não necessariamente um inimigo, mas alguém que não se comporta como amigo, no sentido familiar do termo, e a quem Orestes punha toda a esperança de salvação. Ao contrário de Menelau, que quebra o vínculo de philía, no sentido do parentesco, com o sobrinho; é em Pílades que Orestes encontrará todo o apoio:

... Pílades, o mais amado dos mortais... ${ }^{18}$

Assim, Pílades é o amigo que o acompanha desde a Fócida. E encerra seu diálogo com Menelau fazendo uma reflexão geral acerca do homem fiel (pistòs... anèr, v.727):

$\mathrm{Na}$ adversidade, um homem leal é mais aprazível à vista do que a bonança aos marinheiros. ${ }^{19}$

Após essa reflexão, Pílades entra em cena e dá provas da sua excelência acerca das palavras que Orestes termina de proferir. Pílades vem avisar a Orestes a decisão da assembleia de matar ou não Orestes e Electra. E com palavras de amizade, Pílades se dirige ao amigo, situando-o no lugar que ocupa na sua vida:

(...) Que vais fazer, tu que és para mim o mais querido dos companheiros, e dos amigos e da família? ${ }^{20}$

16 Pílades, que também ajudou no matricídio. (Orestes, v.406, trad. de Augusta Fernanda de Oliveira e Silva).

17 Mas vejo aqui o mais querido dos mortais, Pílades, que vem correndo do país dos fócios. (Ibidem, v.725)

18 Ibidem, v.725.

19 Ibidem, vv.727-28.

20 Ibidem, vv.732-33. 
Ao romper o silêncio, Pílades evidencia a importância que Orestes tem para ele. O superlativo phíltath' conduz a sequência representativa do vínculo que Pílades estabelece com Orestes. Assim, este é o mais caro dos que têm a sua idade (helíkon, v.732), dos amigos (phílon, v.733) e dos parentes (syngenéias, v.733). A primeira identidade de Pílades com Orestes é etária. Os dois partilham do mesmo tempo, participam, nesse sentido, do mesmo grupo. Daí, advém a afinidade, tornando-se amigos. Mais interessante, talvez, seja a terceira identidade: a família, o grau de parentesco. Mesmo entre os parentes, Pílades põe Orestes como preferidos àqueles. Ao proferir "tu és tudo isso para mim (v.733)", Pílades atribui a Orestes a condição da sua existência, no sentido em que aponta Aristóteles, em Ética a Nicômacos, de que é impossível viver sem amigos, ao mesmo tempo que propõe um princípio de identidade total, no sentido plutarquiano, como já mencionado, de que o amigo é outro eu. Esse princípio torna-se mais óbvio, quando Pílades sugere morrerem juntos (synkataskáptois àn hemãs, v.735), pois entre os amigos todas as coisas são comuns (koiná,v.735): a desgraça e a felicidade, como afirma Pílades em 798-803:

Sim, pois era tua inimiga. Mas para que antes não te surpreenda o voto dos argivos, apressa-te a cingir aos meus flancos os teus flancos entorpecidos pela doença! Que eu pela cidade te levarei, pouco me importando com a multidão, sem me envergonhar de coisa alguma. Pois, como hei de mostrar que sou amigo, se não te ajudo nas tremendas circunstâncias em que estás?21

Diante do ato e das palavras de Pílades, Orestes faz o elogio ao amigo reconhecendo que o laço de sangue (syngenés, v.804) não é suficiente para se fazer um amigo e relembra o provérbio com o qual também encerramos esse trabalho, adequando-o ao contexto da ação na qual se envolvem Orestes e Pílades:

... todo homem que, pelo seu caráter, é unido a outro, ainda que seja um estranho, vale mais tê-lo como amigo do que ser parentes sem conta. ${ }^{22}$

\section{Considerações finais}

A literature grega, posterior a Eurípides, parece ter visto no mais longo diálogo de Pílades e Orestes, o modelo ideal de amigo que permite unir Orestes e

\footnotetext{
21 Ibidem, vv.798-803.
}

22 Ibidem, vv.805-06. 
Pílades, como vemos, por exemplo, na História de Orestes e Pílades, de Luciano. A relação que Luciano estabelece entre Orestes e Pílades é a de amante-amado. O autor diz que os dois navegaram na vida, como navegaram no mar, para que ambos, conjuntamente, dessem morte a Clitemnestra, como se os dois fossem filhos de Agamêmnon. Luciano diz, ainda, que Egisto foi morto pelos dois e que Pílades sofreu mais do que o amigo pelo castigo que aquele havia recebido. Quando Orestes foi condenado, Pílades, a exemplo de Damon (vide a nota 1), intercedeu pelo amigo, e a amizade entre eles não conheceu fronteiras, pois Pílades acompanhou o amante para além da Grécia.

Quando chegam a Táuris, quando Orestes tem uma crise por causa da doença, Ṕ́lades limpa a espuma da boca de Orestes e, cuidando do amigo, o cobriu com seu "manto bem tecido", agindo não somente como amigo, mas como pai. E, por fim, no episódio da carta, quando foi determinado que um deles deveria ficar para ser morto, enquanto o outro iria a Micenas para levar notícias de Ifigênia aos seus, todos dois quiseram ficar um em lugar do outro, pois quem salvasse a vida do amigo, salvaria sua própria vida. Orestes recusou a levar a carta, dizendo que Ṕlades era mais digno de levá-la, agindo mais como amante do que como amado. "Pois", diz Orestes, "a morte deste homem seria um grande pesar para mim..."

Assim, a amizade ou o amor entre Pílades e Orestes se encena como algo difícil de determinar, por causa da afeição recíproca que envolve a relação euoutro; o outro considerado como o amigo, ou como quer a tradição pós-clássica, amante-amado, visto que tal relação se apresenta como um espelho, como bem aponta Luciano, uma vez que a afeição do eu/amante/amigo é refletida a partir da do outro/amado/amigo.

BiBLIOGRAFIA

Aristóteles (2001): Ética a Nicômacos. Editora da Universidade de Brasília, Brasília. Tradução de Mário da Gama Kury.

ÉsQuilo (2004): Coéforas. Iluminuras/FAPESP, São Paulo. Tradução de Jaa Torrano. EuríPides (1999): Orestes. Editora da Universidade de Brasília, Brasília. Tradução de Augusta Fernanda de Oliveira e Silva.

SEAford, Richard (ed.), (1998): Reciprocity in ancient Greece. Clarendon Press Oxford Press, Oxford.

Homero (2001): Ilíada. Ediouro, Rio de Janeiro. Tradução de Carlos Alberto Nunes. 
Homero (1976): Odisséia. Ediouro, Rio de Janeiro. Tradução de Carlos Alberto Nunes.

Píndaro (2002): Odas y framentos. Editorial Gredos, S.A., Madrid. Traducción de Alfonso Ortega.

Ribeiro Jr, W.A: "Hesíodo Fr. 23a Merkelbach-West: tradução e comentários". Caliope, 2004, n.12, p.84-92.

Sophocles (1997): Electra. Cambridge University Press, Cambridge.

Resumen: Los poetas épicos son poco explícitos sobre la relación de amistad entre Pílades y Orestes; en la poesía trágica, los dramaturgos explicitarán mejor el vínculo entre los dos amigos: En Coéforas, de Esquilo, Pílades aconseja al amigo como debe actuar con relación al asesinato de la madre y, en Electra, pese al silencio que Sófocles imprime a Pílades, ese permanece, aún, como el fiel amigo de Orestes. Y en las tragedias Electra y Orestes, Eurípides menciona el afecto entre Pílades y Orestes. Este artículo pretende analizar el papel de la amistad entre Orestes y Pílades en las obras anteriormente citadas.

Palabras clave: Tragedia griega, amistad, Orestes y Pílades 